\title{
Surgical management of left ventricular outflow tract obstruction in a specialized hypertrophic obstructive cardiomyopathy center
}

\author{
Kevin Hodges, MD, ${ }^{\mathrm{a}}$ Carlos Godoy Rivas, MD,${ }^{\mathrm{b}}$ José Aguilera, MD, ${ }^{\mathrm{c}}$ Robert Borden, BS, ${ }^{\mathrm{d}}$ \\ Alaa Alashi, MD, ${ }^{\mathrm{c}}$ Eugene H. Blackstone, MD, ${ }^{\mathrm{a}, \mathrm{e}}$ Milind Y. Desai, MD, ${ }^{\mathrm{c}}$ and Nicholas G. Smedira, MD
}

\section{ABSTRACT}

Objectives: This study evaluates operative approach and contemporary surgical outcomes in the management of left ventricular outflow tract obstruction by a single surgeon at a high-volume, specialized hypertrophic cardiomyopathy center.

Methods: This is a retrospective review of 1559 consecutive operations for left ventricular outflow tract obstruction from 2005 to 2015. Demographic profiles, echocardiogram-derived ventricular morphology and hemodynamics, operative data, and in-hospital outcomes were analyzed.

Results: Of the 1559 operations, 586 were isolated septal myectomies, 522 were myectomies with mitral valve or subvalvular apparatus intervention, 422 were myectomies with another concomitant procedure, and 29 were isolated mitral valve interventions without myectomy. Common mitral valve interventions included anterior leaflet shortening (16\%), chordae tendineae resection $(9.8 \%)$, papillary muscle resection $(7.2 \%)$, and papillary muscle reorientation $(7.5 \%)$. Ninety-two patients underwent mitral valve replacement, 42 for left ventricular outflow tract obstruction and 50 for intrinsic mitral valve pathology. Patients undergoing mitral interventions had thinner septums $(18 \pm 0.4 \mathrm{~mm}$ vs $22 \pm 0.5 \mathrm{~mm}$, $P<.001)$ and less myocardium removed $(6.2 \pm 3.5 \mathrm{~g}$ vs $8.8 \pm 3.8 \mathrm{~g}, P<.001)$ than patients without a mitral intervention. Prevalence of in-hospital permanent pacemaker insertion was $4.2 \%(\mathrm{n}=1334)$ for complete heart block and $1.1 \%$ $(\mathrm{n}=464)$ for isolated septal myectomy with normal preoperative conduction. Overall, there were 2 postoperative ventricular septal defects $(0.13 \%)$ and none for isolated myectomies. Operative mortality was $0.38 \%$.

Conclusions: Septal myectomy can be performed safely with excellent outcomes when the procedure is performed by a highly experienced surgeon in a high-volume, specialized center. A mitral valve intervention is a useful adjunct in patients with moderate hypertrophy. (J Thorac Cardiovasc Surg 2019;157:2289-99)

\footnotetext{
From the ${ }^{\mathrm{a} D e p a r t m e n t s ~ o f ~ T h o r a c i c ~ a n d ~ C a r d i o v a s c u l a r ~ S u r g e r y, ~ H e a r t ~ a n d ~ V a s c u l a r ~}$ Institute; ${ }^{b}$ Department of Internal Medicine, Medicine Institute; ${ }^{\mathrm{c}}$ Cardiovascular Medicine, Heart and Vascular Institute; and ${ }^{\mathrm{e}}$ Quantitative Health Sciences, Research Institute, Cleveland Clinic; and ${ }^{\mathrm{d}}$ Cleveland Clinic Lerner College of Medicine, Cleveland, Ohio.

This study was funded in part by the Gus P. Karos Registry Fund, the David Whitmire Hearst, Jr Foundation, the Marty and Michelle Weinberg and Family Fund, the Mayer Family Fund in Hypertrophic Cardiomyopathy Research, the Polly and W. Neil Rossborough Endowed Chair in Heart Transplantation Research, the Delos M. Cosgrove, MD, Chair for Heart Disease Research, the Peter and Elizabeth C. Tower and Family Endowed Chair in Cardiothoracic Research, the Sheikh Hamdan bin Rashid Al Maktoum Distinguished Chair in Thoracic and Cardiovascular Surgery, the Drs Sidney and Becca Fleischer Heart and Vascular Education Chair,
}

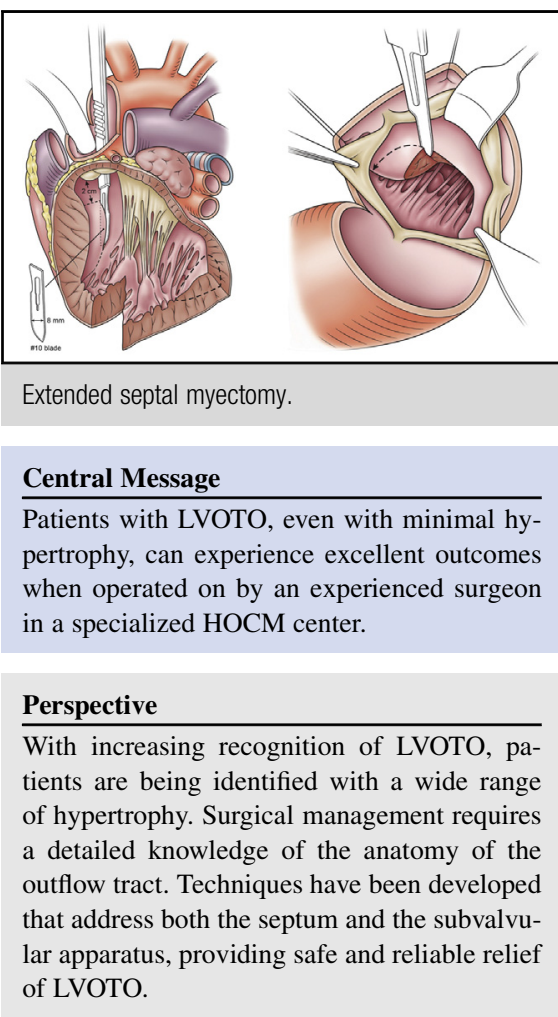

See Commentary on page 2300.
James and Sharon Kennedy, the Slosburg Family Charitable Trust, Stephen and Saundra Spencer, and Martin Nielsen.

Institutional Review Board: Cleveland Clinic Institutional Review Board \#16-082 accepted January 16, 2016.

Read at the 98th Annual Meeting of The American Association for Thoracic Surgery, San Diego, California, April 28-May 1, 2018.

Received for publication April 21, 2018; revisions received Nov 1, 2018; accepted for publication Nov 23, 2018; available ahead of print Feb 16, 2019.

Address for reprints: Nicholas G. Smedira, MD, Department of Thoracic and Cardiovascular Surgery, Cleveland Clinic, 9500 Euclid Ave/Desk J4-1, Cleveland, OH 44195 (E-mail: smedirn@ccf.org).

$0022-5223 / \$ 36.00$

Copyright (c) 2019 by The American Association for Thoracic Surgery

https://doi.org/10.1016/j.jtcvs.2018.11.148 


\section{Abbreviations and Acronyms}

HOCM = hypertrophic obstructive cardiomyopathy

LVOTO $=$ left ventricular outflow tract obstruction

MVR = mitral valve replacement

RBBB = right bundle branch block

SAM = systolic anterior motion

TEE $=$ transesophageal echocardiogram

Scanning this $\mathrm{QR}$ code will take you to the article title page to access supplementary information. To view the AATS Annual Meeting Webcast, see the URL next to the webcast thumbnail.

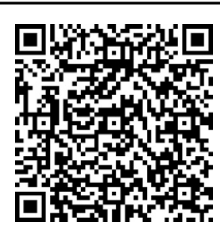

Septal myectomy remains the gold standard for managing left ventricular outflow tract obstruction (LVOTO) in patients with hypertrophic obstructive cardiomyopathy (HOCM). ${ }^{1-4}$ Analysis of the National Inpatient Sample has suggested that this procedure is associated with high mortality and occurrence of complete heart block requiring permanent pacemakers. ${ }^{5}$ However, outcomes are strongly associated with hospital volume, with high-volume centers achieving mortality of less than $1 \%$ and lower permanent pacemaker requirements. ${ }^{6-8}$

Although the role of septal myectomy is clearly established, the role of mitral valve interventions, in combination with myectomy or as isolated procedures, remains controversial. Some have argued that mitral interventions are seldom necessary, whereas others have used these techniques as an adjunct for patients with LVOTO and moderate hypertrophy. ${ }^{9-11}$

The purpose of this study was to assess outcomes of the surgical management of LVOTO by an experienced surgeon at a specialized HOCM center. In particular, we sought to delineate the role of mitral valve interventions in managing LVOTO in patients with limited septal hypertrophy.

\section{PATIENTS AND METHODS Patients}

From January 2005 to December 2015, 1549 patients underwent 1559 operations for LVOTO by a single surgeon (N.G.S.). Operations included 586 isolated septal myectomies, 422 myectomies with a mitral valve intervention, and 522 myectomies with or without a mitral valve intervention but with other concomitant procedures. There were 29 mitral valve interventions without a myectomy for symptomatic LVOTO. Patient baseline characteristics, relevant history, and presenting symptoms are summarized in Table 1. Data were extracted from the Cardiovascular

TABLE 1. Patient characteristics

\begin{tabular}{|c|c|c|c|c|c|}
\hline Characteristic & $\begin{array}{c}\text { All patients } \\
(\mathbf{n}=1559) \\
\text { No. }(\%)\end{array}$ & $\begin{array}{c}\text { Isolated septal } \\
\text { myectomy }(\mathbf{n}=\mathbf{5 8 6}) \\
\text { No. }(\%)\end{array}$ & $\begin{array}{c}\text { Septal myectomy }+ \text { mitral } \\
\text { valve intervention } \\
(\mathbf{n}=\mathbf{4 2 2}) \\
\text { No. }(\%)\end{array}$ & $\begin{array}{c}\text { Septal myectomy } \\
\text { with concomitant } \\
\text { procedure* }(n=522) \\
\text { No. }(\%)\end{array}$ & $\begin{array}{c}\text { Mitral valve } \\
\text { intervention without } \\
\text { myectomy }(n=29) \\
\text { No. }(\%)\end{array}$ \\
\hline Age $(y) \dagger$ & $55 \pm 14$ & $53 \pm 14$ & $53 \pm 13$ & $60 \pm 14$ & $51 \pm 17$ \\
\hline Male & $838(54)$ & $305(52)$ & $232(55)$ & $281(54)$ & $20(71)$ \\
\hline \multicolumn{6}{|l|}{$\begin{array}{l}\text { Previous septal reduction } \\
\text { procedures }\end{array}$} \\
\hline Septal myectomy & $20(1.3)$ & $3(0.51)$ & $6(1.4)$ & $5(1.0)$ & $6(21)$ \\
\hline Alcohol ablation & $20(1.3)$ & $10(1.7)$ & $5(1.2)$ & $4(0.77)$ & $1(3.6)$ \\
\hline Previous PPM or ICD & $226(15)$ & $100(17)$ & $44(10)$ & $81(16)$ & $1(20)$ \\
\hline \multicolumn{6}{|l|}{ Symptoms on presentation } \\
\hline Dyspnea & $886(57)$ & $343(58)$ & $250(59)$ & $268(51)$ & $25(86)$ \\
\hline Syncope & $408(26)$ & $164(28)$ & $114(27)$ & $121(23)$ & $9(31)$ \\
\hline Angina & $775(50)$ & $287(49)$ & 205 (49) & $272(52)$ & $11(38)$ \\
\hline \multicolumn{6}{|l|}{ NYHA functional class } \\
\hline I & $348(22)$ & $138(24)$ & $81(19)$ & $123(24)$ & $6(21)$ \\
\hline II & $755(48)$ & $287(49)$ & $222(53)$ & $235(45)$ & $11(39)$ \\
\hline III & $438(28)$ & $153(26)$ & $116(27)$ & $158(30)$ & $11(39)$ \\
\hline IV & $17(1.1)$ & $8(1.4)$ & $3(0.71)$ & $6(1.1)$ & $0(0)$ \\
\hline \multicolumn{6}{|l|}{ Preoperative medical therapy } \\
\hline Beta-blocker & $1364(88)$ & $526(90)$ & $364(86)$ & $451(86)$ & $23(79)$ \\
\hline Calcium channel blocker & $658(42)$ & $245(42)$ & $173(41)$ & $235(45)$ & $5(17)$ \\
\hline Disopyramide & $108(6.9)$ & $42(7.2)$ & $25(5.9)$ & $41(7.9)$ & $0(0)$ \\
\hline
\end{tabular}

PPM, Permanent pacemaker; $I C D$, implantable cardioverter-defibrillator; NYHA, New York Heart Association. *Septal myectomy with or without mitral valve intervention but with other concomitant procedure. $\nmid$ Mean \pm standard deviation. 


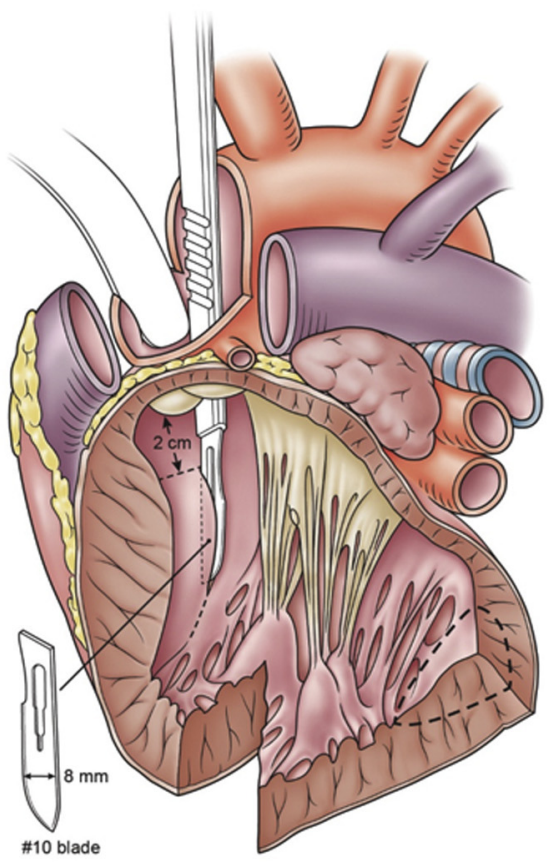

A

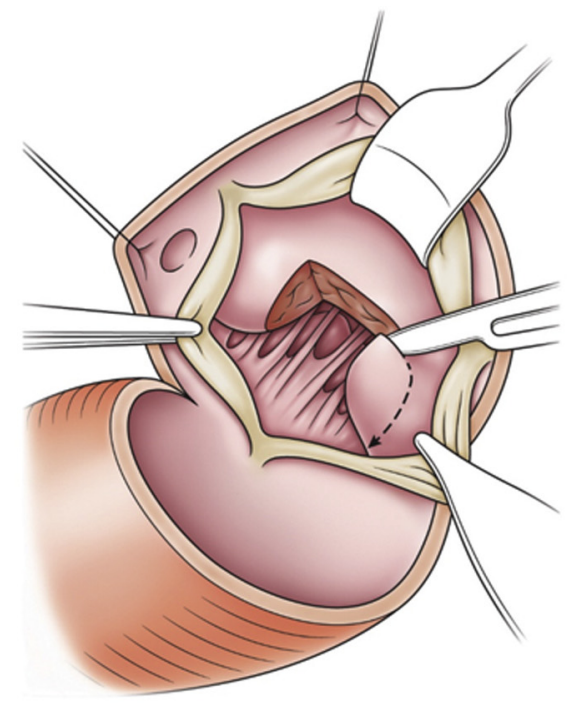

C

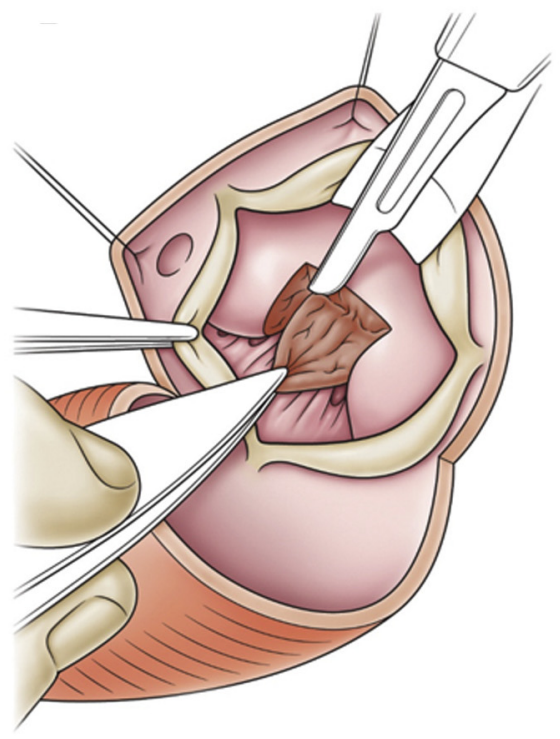

B

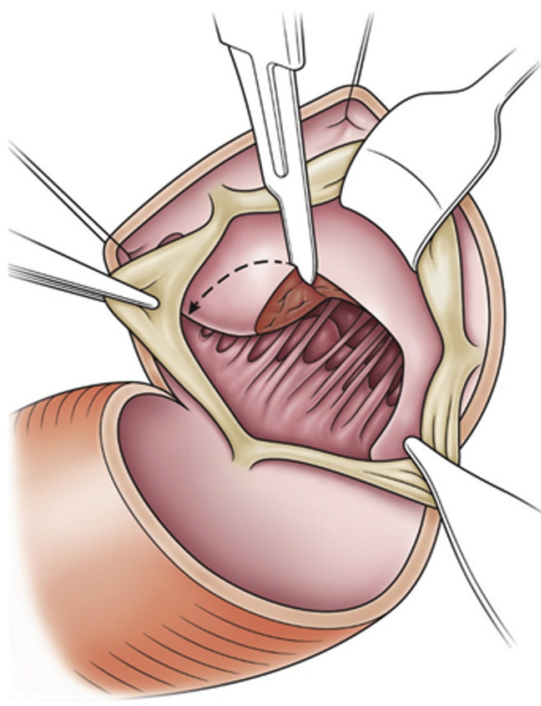

D

FIGURE 1. Extended septal myectomy is a 3-step approach based on location of the leaflet-septal contact identified on TEE. This contact is commonly 18 to $22 \mathrm{~mm}$ below the nadir of the right coronary cusp. Step 1: At this point, 2 parallel incisions are made $10 \mathrm{~mm}$ apart, 4 to $6 \mathrm{~mm}$ deep, and 15 to $20 \mathrm{~mm}$ long, with an inverted \#10 blade (A). These incisions are connected using a \#15 blade, and a rectangle of muscle 10-mm wide by 5-mm thick by 20 -mm long in length is excised (B). Step 2: The edge of this excision is continued to the right trigone, removing another rectangle of muscle (C). Care must be taken to note the thickness of the inferoseptum in the 4-chamber view, because it is often thinner than the anteroseptum seen on the long-axis view. Step 3: The anterior edge of the initial incision is then grasped and continued to the left trigone, removing another rectangle of muscle (D).

Information Registry, a database maintained concurrently with patient care, and by review of electronic medical records. Use of these data for research was approved by the Institutional Review Board, with patient consent waived.

\section{Conduct of the Operation}

To understand the surgical techniques, clarity of descriptive terms is necessary. Width of resection refers to excision of septal muscle from trigone to trigone, depth is measured from the endocardium into the septum, 
and length is the extent toward the apex. Echocardiographic views include the left ventricular long-axis view showing the anteroseptum, which is immediately beneath the right ventricular outflow tract, and the 4-chamber view showing the inferoseptum, which is beneath the membranous septum. The septum beneath the right coronary cusp is not well seen. The base of the ventricle is that area beneath the aortic valve, mid-ventricle is opposite the papillary muscle heads, and apex is beyond the body of the papillary muscles.

Septal myectomies have been performed at the Cleveland Clinic since 1975. Beginning in 1998, the technique was modified as suggested by Yacoub and colleagues, ${ }^{12}$ resulting in a "release" of the trigones. This technique is used in all cases (Figure 1 and Video 1), using the trigones or the outside borders of the papillary muscles to guide the extent of resection, and involves a 3-step approach based on location of the leaflet-septal contact identified on the transesophageal echocardiogram (TEE). This contact is most commonly 18 to $22 \mathrm{~mm}$ below the nadir of the right coronary cusp. If indicated by TEE, the mid- and apical ventricular septum can be excised using this 3-step approach.

Beginning in 2005, an increasing number of patients were referred with LVOTO with limited or no septal hypertrophy. Techniques were developed to address the mechanism of systolic anterior motion (SAM) of the mitral valve and minimize the need for valve replacement. These include plication or resection of the elongated A2 segment of the anterior leaflet, resection of tethering secondary chordae, resection of anomalous papillary muscle heads inserting into the valve, and reorientation of abnormally oriented or excessively mobile papillary muscles (Figure 2). Each of these interventions is performed via a transaortic approach after thorough inspection of the mitral valve and subvalvular apparatus.

For patients with intrinsic mitral valve pathology potentially requiring valve replacement, septal myectomy was used to increase the diameter of the left ventricular outflow tract to accommodate the higher profiles of biologic valves.

\section{Echocardiographic Analysis}

Preoperative structural assessment was primarily based on transthoracic echocardiography, as previously described. ${ }^{13}$ Thickness of the interventricular septum was measured during diastole at the point of leaflet-septal contact during systole. Maximum peak left ventricular outflow tract gradient at rest and on provocation by amyl nitrate, Valsalva maneuver, or exercise was measured using continuous-wave Doppler echocardiography. SAM of the mitral valve at rest or on provocation was noted. Severity of mitral regurgitation was graded by semiquantitative assessment ${ }^{14}$ (grades 0-4), and jet number and direction were noted. Mitral regurgitation was characterized as SAM-associated or not SAM-associated (ie, related or not to intrinsic mitral valve pathology) (Table 2).

Intraoperative TEE was performed in all cases to assess hemodynamic outcomes. Maximum provoked LVOT gradients were obtained with $20 \mu \mathrm{g}$ of isoproterenol or 10 to $20 \mu \mathrm{g} / \mathrm{kg} / \mathrm{min}$ dobutamine. Patients without a chronotropic response were paced at 100 to 110 beats/min. Nitroglycerine was administered to reduce the systolic pressure below $100 \mathrm{~mm} \mathrm{Hg}$. At this time, a gradient was obtained and accepted if less than $36 \mathrm{~mm} \mathrm{Hg}$; $2+$ or less mitral regurgitation was accepted. Direct measurement of LVOT pressure gradient was generally not performed. TEE assessment of gradients must use the transgastric view of the LVOT. Other views can overestimate the gradient by including residual mitral regurgitation or underestimate the gradient by off axis sampling.

In most cases, postoperative transthoracic echocardiogram was performed before hospital discharge or at first follow-up. Maximum provoked gradients were obtained with amyl nitrate and Valsalva whenever possible. For the purpose of analysis, all postoperative echocardiograms within 1 year of operation were queried. The maximum available LVOT gradient and highest degree of mitral regurgitation with each provocative maneuver (ie, amyl nitrate, Valsalva, or exercise) were recorded for each patient.

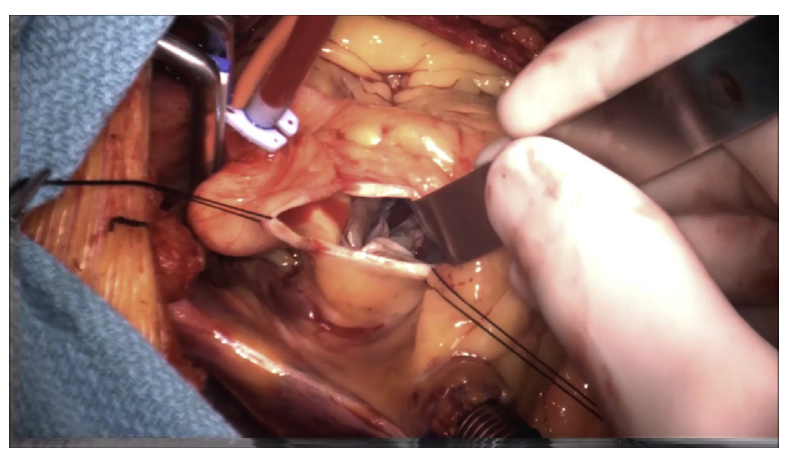

VIDEO 1. Surgical technique for extended septal myectomy. This video includes a complication of clips from 2 unique patients and is intended to demonstrate the steps and technique for this operation. Video available at: https://www.jtcvs.org/article/S0022-5223(18)33514-1/fulltext.

\section{Data Analysis}

Patient characteristics and surgical outcomes were analyzed. To evaluate the role of mitral valve interventions in the surgical treatment of LVOTO, patients were grouped according to performance of a mitral valve intervention or other concomitant procedure at the time of septal myectomy. Prevalence of permanent pacemaker insertion was determined for patients without a preoperative pacemaker or implantable cardioverterdefibrillator who developed complete heart block after the procedure.

\section{Presentation}

Continuous variables are summarized as mean \pm standard deviation or 15 th/50th/85th percentiles, as appropriate. Normality was assessed by comparing the mean \pm standard deviation or 15 th $/ 50$ th/85th percentiles, as well as graphically. The nonparametric Kruskal-Wallis and Wilcoxon rank-sum tests were used to investigate group differences. Categoric variables are summarized as frequencies and percentages, and group comparisons were made using the chi-square test.

\section{RESULTS}

\section{Technical Performance}

Septal myectomy. Most patients underwent basilar septal myectomy, although some had mid-cavitary or apical myectomy or subaortic membrane resection (Table 3). All myectomies were performed via a transaortic approach. Aortic clamp time ranged from $28 \pm 10$ minutes to $60 \pm 26$ minutes for isolated septal myectomy and myectomy with concomitant procedures, respectively. Mean mass of myocardium removed was $8.1 \pm 3.7 \mathrm{~g}$; patients undergoing isolated septal myectomy had the most muscle removed, and those with combined myectomy and mitral valve intervention the least.

Septal myectomy and mitral valve interventions. Mitral valve interventions, in order of decreasing frequency, were anterior leaflet shortening, resection of chordae tendineae, papillary muscle resection, papillary muscle reorientation, and mitral valve replacement (MVR) (Table 3). Frequency of these interventions was inversely related to preoperative septal thickness (Figure 3). Mass of myocardium removed decreased with increasing complexity of the mitral valve intervention (Figure 4). 

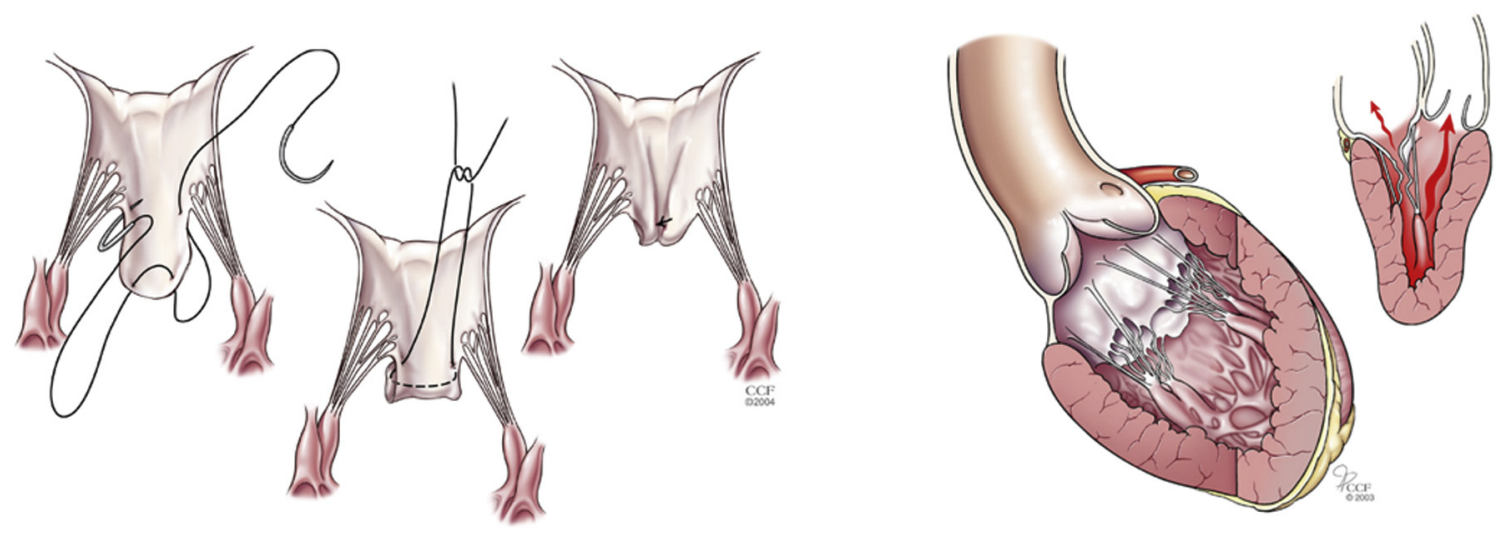

A

B
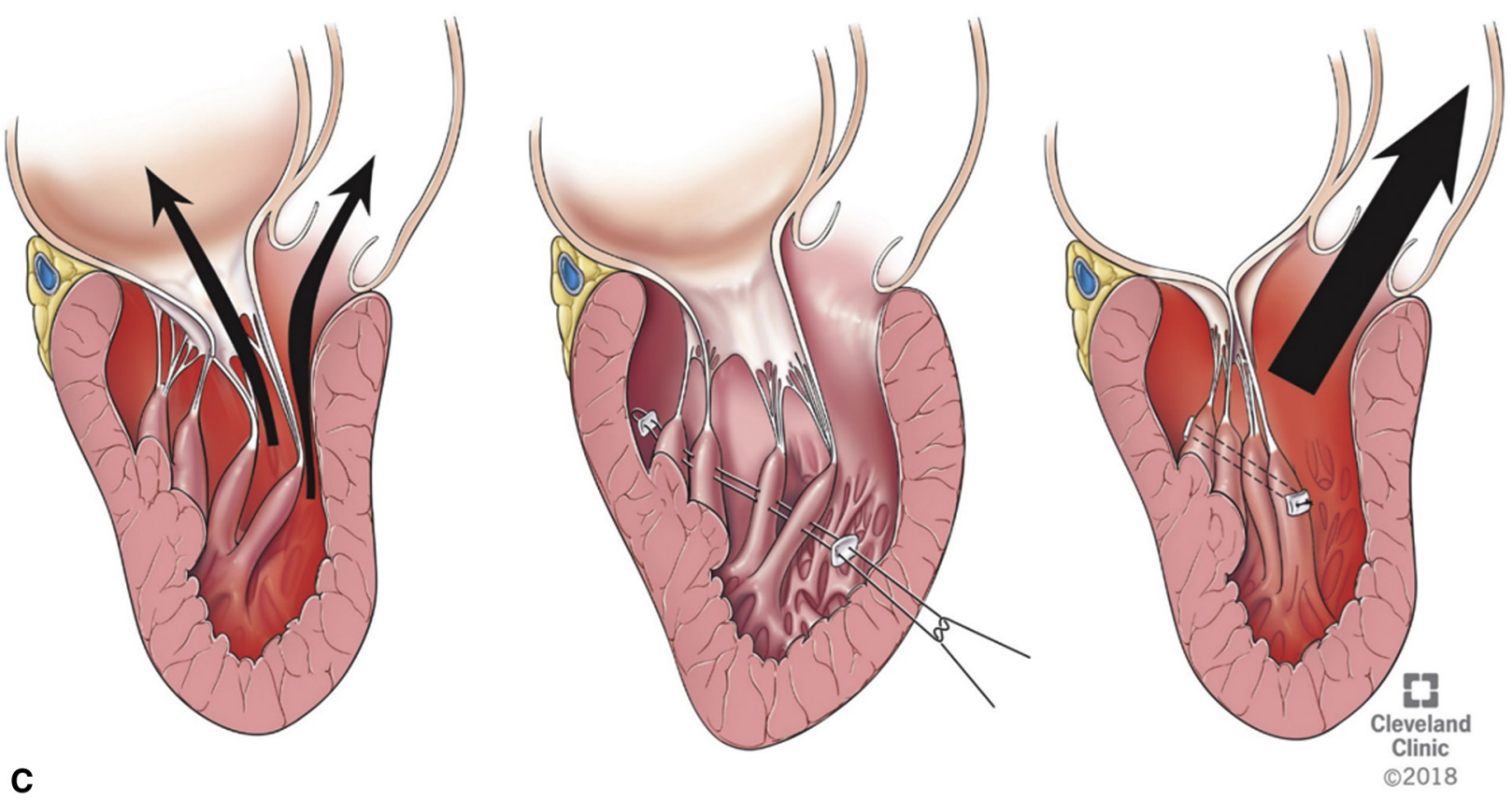

C

FIGURE 2. Commonly used mitral valve interventions. A, Plication of elongated anterior mitral leaflet. B, Tethering secondary chordae are often present on the anterior mitral leaflet that pull the leaflet into the left ventricular outflow tract. Resectioning these chordae allows the zone of coaptation to move posteriorly, away from the outflow tract. C, Large, excessively mobile or anteriorly displaced papillary muscles can contribute directly to the LVOTO and pull the anterior leaflet toward the outflow tract, potentiating SAM. Papillary muscle reorientation is performed by tacking anterior papillary muscle heads to posterior heads, moving the papillary muscles and mitral valve zone of coaptation away from the outflow tract.

Septal myectomy and mitral valve replacement. Of 72 septal myectomies with MVR, 55 involved LVOTO and intrinsic mitral pathology and 17 were performed exclusively for LVOTO (Table 3).

Isolated mitral valve interventions for left ventricular outflow tract. Twenty-six patients underwent 29 isolated mitral valve procedures without a myectomy. Thirteen underwent reoperative MVR for recurrent LVOTO after previous myectomy or mitral valve intervention, including 2 papillary muscle reorientations and 1 use of restrictive artificial chordae. Three patients underwent MVR when intraoperative TEE demonstrated persistent LVOTO after attempted repair. Four patients underwent MVR for LVOTO with minimal septal hypertrophy and 4 for LVOTO combined with severe intrinsic valvular pathology. Six patients underwent papillary muscle reorientation with satisfactory reduction in outflow tract gradients.

\section{Type of Mitral Valve Prosthesis}

For the 92 MVRs, 40 (44\%) were with mechanical prostheses and $52(56 \%)$ were with biologic prostheses. Mechanical prostheses were more commonly used in MVR 
TABLE 2. Preoperative echocardiographic data

\begin{tabular}{|c|c|c|c|c|c|}
\hline Variable & $\begin{array}{l}\text { All patients } \\
(\mathbf{n}=1559) \\
\text { No. }(\%) \text { or } \\
\text { mean } \pm \text { SD }\end{array}$ & $\begin{array}{c}\text { Isolated septal } \\
\text { myectomy }(n=586) \\
\text { No. }(\%) \text { or } \\
\text { mean } \pm \text { SD }\end{array}$ & $\begin{array}{c}\text { Septal myectomy }+ \text { mitral } \\
\text { valve intervention } \\
(n=422) \\
\text { No. }(\%) \text { or mean } \pm \text { SD }\end{array}$ & $\begin{array}{c}\text { Septal myectomy with } \\
\text { concomitant procedure* } \\
(n=522) \\
\text { No. }(\%) \text { or mean } \pm \text { SD }\end{array}$ & $\begin{array}{c}\text { Mitral valve } \\
\text { intervention without } \\
\text { myectomy }(n=29) \\
\text { No. }(\%) \text { or mean } \pm \text { SD }\end{array}$ \\
\hline Ejection fraction (\%) & $62 \pm 6.3(\mathrm{n}=1523)$ & $62 \pm 5.9(\mathrm{n}=577)$ & $62 \pm 6.1(\mathrm{n}=415)$ & $62 \pm 6.9(\mathrm{n}=505)$ & $63 \pm 5.7(\mathrm{n}=26)$ \\
\hline $\begin{array}{l}\text { Interventricular septal } \\
\text { thickness }(\mathrm{cm})\end{array}$ & $2.0 \pm 0.48(\mathrm{n}=1517)$ & $2.1 \pm 0.52(\mathrm{n}=576)$ & $1.8 \pm 0.38(\mathrm{n}=417)$ & $2.0 \pm 0.44(\mathrm{n}=498)$ & $1.4 \pm 0.41(\mathrm{n}=26)$ \\
\hline \multicolumn{6}{|c|}{ LVOT peak gradient $(\mathrm{mm} \mathrm{Hg}$ ) } \\
\hline Resting & $63 \pm 46(n=1460)$ & $66 \pm 46(\mathrm{n}=563)$ & $64 \pm 48(\mathrm{n}=397)$ & $60 \pm 44(\mathrm{n}=477)$ & $7.2 / 13 / 81 \dagger(\mathrm{n}=23)$ \\
\hline Amyl nitrate & $100 \pm 42(\mathrm{n}=405)$ & $101 \pm 40(\mathrm{n}=152)$ & $108 \pm 41(n=114)$ & $90 \pm 44(\mathrm{n}=122)$ & $101 \pm 47(\mathrm{n}=17)$ \\
\hline Valsalva & $89 \pm 48(\mathrm{n}=463)$ & $91 \pm 47(\mathrm{n}=187)$ & $90 \pm 52(\mathrm{n}=123)$ & $87 \pm 47(\mathrm{n}=143)$ & $76 \pm 28(\mathrm{n}=10)$ \\
\hline Exercise & $118 \pm 52(\mathrm{n}=467)$ & $120 \pm 51(\mathrm{n}=203)$ & $124 \pm 54(\mathrm{n}=146)$ & $108 \pm 52(\mathrm{n}=117)$ & $140(\mathrm{n}=1)$ \\
\hline Mitral regurgitation grade & $(\mathrm{n}=1397)$ & $(\mathrm{n}=541)$ & $(\mathrm{n}=387)$ & $(\mathrm{n}=469)$ & $(\mathrm{n}=24)$ \\
\hline None/trivial & 247 (17) & $94(17)$ & $75(19)$ & $71(15)$ & $7(29)$ \\
\hline Mild & 407 (29) & $169(31)$ & $100(26)$ & $135(29)$ & $3(12)$ \\
\hline Moderate & $480(34)$ & $169(31)$ & $143(37)$ & $159(34)$ & $9(38)$ \\
\hline Severe & $287(20)$ & $109(20)$ & $69(18)$ & $104(22)$ & $5(20)$ \\
\hline
\end{tabular}

SD, Standard deviation; $L V O T$, left ventricular outflow tract. *Septal myectomy with or without mitral valve intervention but with other concomitant procedure. $\dagger 15$ th/50th/85th percentiles.

without myectomy $(65 \%$ without vs $38 \%$ with myectomy, $P=.03)$; there was no significant age difference between these groups $(55 \pm 14$ years without vs $60 \pm 13$ years with myectomy, $P=.15$ ).

\section{Hemodynamic Outcomes}

Across all groups, mean postoperative resting left ventricular outflow tract gradient was approximately $15 \mathrm{~mm}$ $\mathrm{Hg}$ and maximum provoked gradient was approximately $25 \mathrm{~mm} \mathrm{Hg}$ (Table 4). Most patients had no greater than mild postoperative mitral regurgitation, and $3 \%$ had severe regurgitation (Table 4). There were no significant differences in hemodynamic outcomes between patients undergoing isolated myectomy and patients undergoing myectomy with mitral valve intervention.

\section{Safety}

Median hospital length of stay was 6 days; hospital length of stay was longest for patients with septal myectomy with or without a mitral valve procedure but with concomitant procedures. Prevalence of new pacemaker insertion for complete heart block was $4.2 \%$, varying according to presence of concomitant procedures and preexisting right bundle branch block (RBBB). All patients with preoperative complete RBBB required a new pacemaker, compared with $10 \%$ of those with incomplete RBBB and $1.5 \%$ of those with no preoperative RBBB. There were 2 iatrogenic ventricular septal defects and none for septal myectomy with or without a mitral valve procedure. Overall operative mortality was $0.38 \%$. Mortality for isolated septal myectomy, septal myectomy with or without a mitral valve intervention but with other concomitant procedure, and MVR was $0.34 \%, 0.77 \%$, and $1.1 \%$, respectively.

\section{DISCUSSION \\ Principal Findings}

When performed by a dedicated team, surgical treatment of LVOTO reliably eliminates LVOTO with preservation of the mitral valve and with low operative mortality and need for a permanent pacemaker. The majority of patients with septal thickness greater than $18 \mathrm{~mm}$ can be treated with myectomy alone. As the degree of hypertrophy decreases, mitral valve interventions become an increasingly important component of the procedure and can be used to avoid MVR and potentially reduce the likelihood of too extensive a myectomy and generation of a ventricular septal defect.

\section{Evolution of Surgical Techniques}

Treatment of LVOTO has traditionally focused on the hypertrophied septum as the mechanism causing SAM of the mitral valve. In the late 1950s and early 1960s, Drs Andrew Morrow and Edwin Brockenbrough treated a new entity causing LVOTO that they called "idiopathic hypertrophic subaortic stenosis." ${ }^{15}$ They surmised that the surgical treatment is analogous to the procedures treating pyloric stenosis or a Heller myotomy for "cardiospasm." Continuous coronary perfusion allowed Morrow to operate on the beating heart, performing a long vertical myotomy followed by a deep finger fracture of the muscle within the myotomy. He noted by palpation that the sphincter-like contraction and narrowing of the left ventricular outflow tract diminished or disappeared with the myotomy.

Morrow later modified the technique using a $10-\mathrm{mm}-$ wide, 15-mm-deep, 4-cm-long rectangular myectomy. ${ }^{16}$ 


\begin{tabular}{|c|c|c|c|c|c|}
\hline Variable & $\begin{array}{c}\text { All patients } \\
(\mathrm{n}=1559) \text { No. }(\%) \\
\text { or mean } \pm \text { SD }\end{array}$ & $\begin{array}{c}\text { Isolated septal } \\
\text { myectomy } \\
(\mathbf{n}=\mathbf{5 8 6}) \\
\text { No. }(\%) \text { or } \\
\text { mean } \pm \text { SD }\end{array}$ & $\begin{array}{c}\text { Septal myectomy }+ \text { mitral } \\
\text { valve intervention } \\
(n=422) \\
\text { No. }(\%) \text { or } \\
\text { mean } \pm \text { SD }\end{array}$ & $\begin{array}{c}\begin{array}{c}\text { Septal myectomy } \\
\text { with concomitant }\end{array} \\
\text { procedure* }(n=522) \\
\text { No. }(\%) \text { or mean } \pm \text { SD }\end{array}$ & $\begin{array}{c}\text { Mitral valve } \\
\text { intervention } \\
\text { without myectomy } \\
(\mathbf{n}=29) \\
\text { No. }(\%) \text { or } \\
\text { mean } \pm \text { SD }\end{array}$ \\
\hline Aortic clamp time (min) & $40 \pm 24$ & $28 \pm 10$ & $35 \pm 18$ & $60 \pm 26$ & $52 \pm 14$ \\
\hline CPB time (min) & $53 \pm 29$ & $38 \pm 15$ & $46 \pm 22$ & $75 \pm 26$ & $67 \pm 21$ \\
\hline $\begin{array}{l}\text { Myectomy type } \\
\text { Basilar } \\
\text { Mid-cavitary } \\
\text { Apical } \\
\text { Subaortic membrane } \\
\text { None }\end{array}$ & $\begin{array}{c}1514(97) \\
34(2.2) \\
14(0.90) \\
41(2.7) \\
29(1.9)\end{array}$ & $\begin{aligned} & 581(99) \\
& 14(2.4) \\
& 3(0.51) \\
& 2(0.34) \\
&-\end{aligned}$ & $\begin{array}{l}420(99) \\
6(1.4) \\
3(0.71) \\
9(2.1) \\
-\end{array}$ & $\begin{array}{r}513(98) \\
14(2.7) \\
8(1.5) \\
30(5.7) \\
-\end{array}$ & N/A \\
\hline Myocardial mass removed (g) & $8.1 \pm 3.7(\mathrm{n}=951)$ & $9.1 \pm 3.9(\mathrm{n}=387)$ & $6.6 \pm 3.2(\mathrm{n}=250)$ & $8.2 \pm 3.5(\mathrm{n}=313)$ & N/A \\
\hline Concomitant procedures & & N/A & & & \\
\hline MVR & $92(5.9)$ & & $15(3.6)$ & $57(11)$ & $20(69)$ \\
\hline $\begin{array}{c}\text { Other mitral valve } \\
\text { intervention }\end{array}$ & $582(37)$ & & $407(96)$ & $157(30)$ & $15(52)$ \\
\hline AML shortening & $243(16)$ & & $186(44)$ & $54(10)$ & $3(10)$ \\
\hline $\begin{array}{l}\text { Resection of chordae at } \\
\text { tendineae }\end{array}$ & $153(9.8)$ & & $119(28)$ & $34(6.5)$ & $0(0)$ \\
\hline $\begin{array}{l}\text { Papillary muscle } \\
\text { resection }\end{array}$ & $113(7.2)$ & & $83(20)$ & $28(5.4)$ & $2(6.9)$ \\
\hline $\begin{array}{l}\text { Papillary muscle at } \\
\text { reorientation }\end{array}$ & $116(7.4)$ & & $92(22)$ & $14(2.7)$ & $9(31)$ \\
\hline CABG & $189(12)$ & & - & $189(36)$ & - \\
\hline Aortic valve replacement & $95(6.1)$ & & - & $95(18)$ & - \\
\hline $\begin{array}{l}\text { Maze/pulmonary valve } \\
\text { isolation }\end{array}$ & $143(9.4)$ & & - & $142(27)$ & $1(3.4)$ \\
\hline
\end{tabular}

$S D$, Standard deviation; $C P B$, cardiopulmonary bypass time; $N / A$, not available; $M V R$, mitral valve replacement; $A M L$, anterior mitral leaflet; $C A B G$, coronary artery bypass grafting. *Septal myectomy with or without mitral valve intervention but with other concomitant procedure.

Noteworthy is the radical depth of the myectomy and the fact that the transverse incision connecting the myotomies began very high, within a few millimeters of the base of the right coronary cusp of the aortic valve.

An important modification of the surgical technique was suggested by Sir Magdi Yacoub and colleagues, ${ }^{12}$ description of the mobilization of the fibrous trigones for severe LVOTO, first presented at the annual meeting of The American Association for Thoracic Surgery in May 1998. Dr Frank Hanley commented that he has noted “....an important amount of encroachment of fibrous and fibromuscular tissue onto the trigones [in patients with HOCM]... which causes an incomplete subaortic conus, which, with dynamic contraction, is responsible for so-called SAM. We believe that this is a much better explanation than that involving a Bernoulli effect, pulling the mitral valve into the outflow tract in some mysterious way.", 12

Other investigators questioned the role of the Venturi effect as an explanation for SAM. Jiang and colleagues ${ }^{17}$ found that SAM of the valve began before ejection, involving only the central portion of the leaflet. The echocardiogram-derived explanation for early SAM consisted of 4 components: anteriorly and inwardly displaced papillary muscles resulting in central chordal laxity, A2 free-edge cupping, leaflet elongation, and a leaflet coaptation point closer to the mitral annulus. Maron and colleagues ${ }^{18}$ have shown that both the anterior and posterior leaflets of patients with hypertrophic cardiomyopathy are significantly longer than normal. We used these observations to develop surgical interventions that could be used to treat the increasing number of patients referred with symptomatic LVOTO and minimal left ventricular hypertrophy.

\section{Role of Mitral Valve Repair in the Management of Left Ventricular Outflow Tract}

For patients with thin septums and LVOTO, mitral valve interventions can be used to alleviate obstruction as an adjunct to a limited myectomy or as a sole procedure. Our data show that this approach allows for excellent 


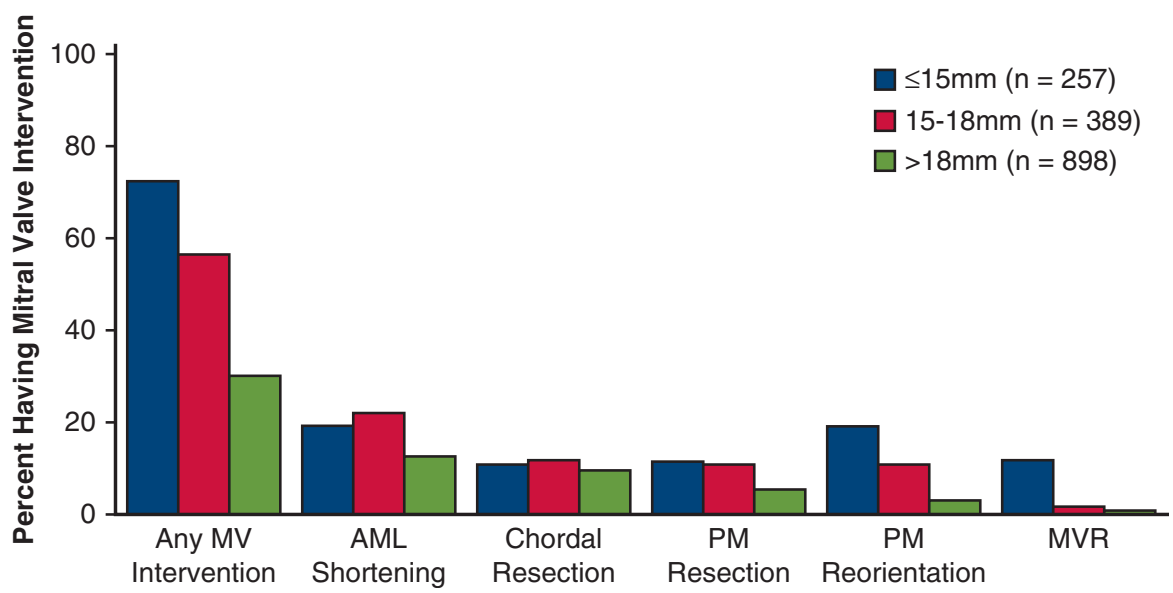

FIGURE 3. Frequency of mitral valve interventions according to septal thickness on preoperative echocardiogram. $M V$, Mitral valve; $A M L$, anterior mitral leaflet; $P M$, papillary muscle; $M V R$, mitral valve replacement.

hemodynamic outcomes with a high degree of safety. Few patients underwent papillary muscle reorientation as the sole therapy for LVOTO. Most patients undergoing papillary muscle reorientation had a small myectomy with excellent results. The efficacy of this technique will require longer-term follow-up. Improvements in selection strategy will help better delineate which patients will benefit from isolated papillary muscle reorientation.

The decision to perform papillary muscle reorientation is based on a thorough intraoperative inspection of the mitral valve and subvalvular apparatus. Some magnetic resonance imaging and echocardiogram views can suggest the possibility of using this technique, but we have found that direct inspection is the only way to see if the anatomy is appropriate for this maneuver. In essence, a very mobile papillary muscle head can be attached to a more posterior head of the same papillary muscle complex as long as this posterior head is fixed to the posterior wall. That anatomic feature-a fixed structure to anchor the mobile head-is the key to the operation and is variably present.

Rates of mitral valve intervention have been noted to vary among HCM centers. Notably, authors from the Mayo Clinic report a very low rate of mitral valve intervention. ${ }^{19}$ The reason for this variability is uncertain, but we suspect 2 key factors. First, there may be important differences in referral patterns based on patient groups and support networks within the relatively small community of patients with HCM. Second, as we have become increasingly comfortable with recognizing mitral valve abnormalities and performing these interventions, our threshold to include a mitral valve intervention as a component of our operative plan has lowered.

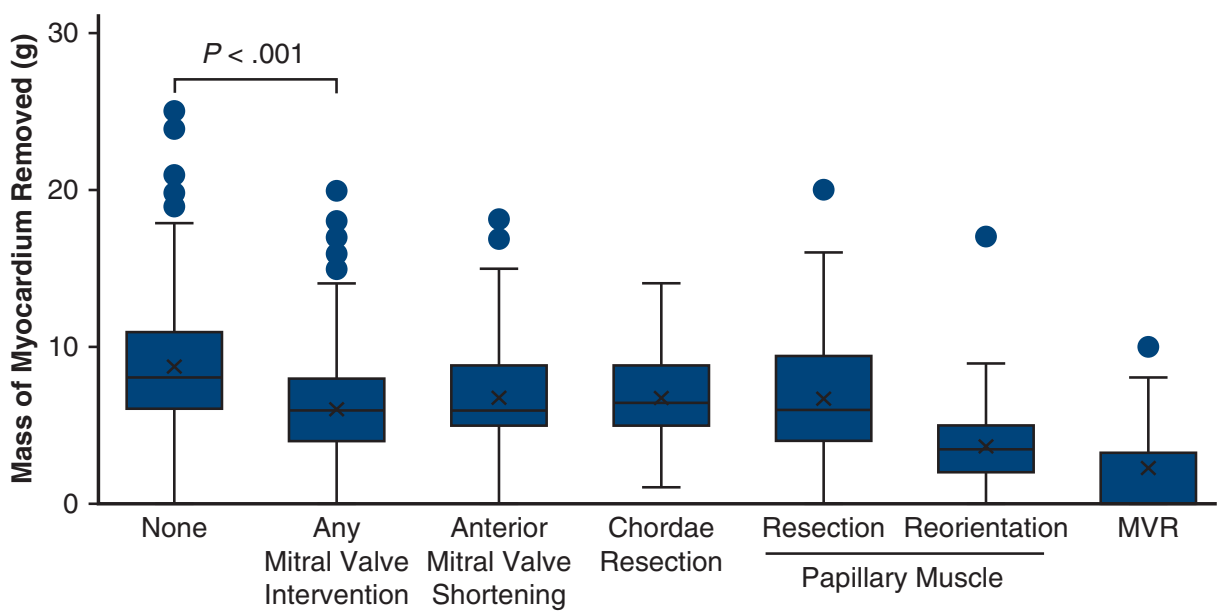

FIGURE 4. Mass of myocardium excised according to mitral valve intervention. Patients undergoing mitral valve interventions had significantly less myocardium removed than patients undergoing myectomy alone $(6.2 \pm 3.5 \mathrm{vs} 8.8 \pm 3.8 \mathrm{~g}, P<.001)$. MVR, Mitral valve replacement. 


\begin{tabular}{|c|c|c|c|c|c|}
\hline Variable & $\begin{array}{l}\text { All patients }(n=1559) \\
\quad \text { No. }(\%) \text { or } \\
\text { mean } \pm \text { SD }\end{array}$ & $\begin{array}{c}\text { Isolated septal } \\
\text { myectomy }(n=586) \\
\text { No. }(\%) \text { or mean } \pm \text { SD }\end{array}$ & $\begin{array}{c}\text { Septal myectomy }+ \text { mitral } \\
\text { valve intervention } \\
(n=422) \\
\text { No. }(\%) \text { or mean } \pm \text { SD }\end{array}$ & $\begin{array}{c}\text { Septal myectomy with } \\
\text { concomitant procedure* } \\
(n=522) \\
\text { No. }(\%) \text { or mean } \pm \text { SD }\end{array}$ & $\begin{array}{c}\text { Mitral valve } \\
\text { intervention without } \\
\text { myectomy }(n=29) \\
\text { No. }(\%) \text { or } \\
\text { mean } \pm \text { SD }\end{array}$ \\
\hline \multicolumn{6}{|l|}{ Postoperative LVOT gradient } \\
\hline Resting & $15 \pm 8.9(\mathrm{n}=1355)$ & $15 \pm 8.1(\mathrm{n}=523)$ & $15 \pm 8.4(\mathrm{n}=395)$ & $15 \pm 10(\mathrm{n}=428)$ & $14 \pm 9.6(\mathrm{n}=9)$ \\
\hline Amyl nitrate & $25 \pm 16(\mathrm{n}=1026)$ & $25 \pm 17(\mathrm{n}=435)$ & $26 \pm 16(n=297)$ & $24 \pm 14(\mathrm{n}=291)$ & $33 \pm 30(\mathrm{n}=3)$ \\
\hline Valsalva & $17 \pm 9.7(\mathrm{n}=502)$ & $17 \pm 9.7(\mathrm{n}=205)$ & $17 \pm 9.0(\mathrm{n}=150)$ & $18 \pm 10(\mathrm{n}=144)$ & $12 \pm 13(\mathrm{n}=3)$ \\
\hline Exercise & $17 \pm 9.7(\mathrm{n}=7)$ & $20 \pm 7.1(\mathrm{n}=2)$ & $10(\mathrm{n}=2)$ & $19 \pm 14(\mathrm{n}=3)$ & - \\
\hline $\begin{array}{l}\text { Postoperative mitral } \\
\text { regurgitation grade }\end{array}$ & $(\mathrm{n}=1437)$ & $(\mathrm{n}=549)$ & $(\mathrm{n}=395)$ & $(\mathrm{n}=469)$ & $(\mathrm{n}=24)$ \\
\hline None/trivial & $668(46)$ & $231(42)$ & $206(52)$ & $210(45)$ & $21(88)$ \\
\hline Mild & $476(34)$ & $189(34)$ & $124(31)$ & $162(34)$ & $1(4.2)$ \\
\hline Moderate & $250(17)$ & $112(20)$ & $56(14)$ & $81(17)$ & $1(4.2)$ \\
\hline Severe & $43(3.0)$ & $17(3.1)$ & $9(2.3)$ & $16(3.4)$ & $1(4.2)$ \\
\hline $\begin{array}{l}\text { New permanent pacemaker for } \\
\text { complete heart block }\end{array}$ & $55 / 1334(4.2)$ & $17 / 486(3.5)$ & $13 / 378(3.4)$ & $25 / 441(5.7)$ & $0 / 29(0)$ \\
\hline No preoperative RBBB & $19 / 1280(1.5)$ & $5 / 464(1.1)$ & $5 / 367(1.4)$ & $9 / 420(2.1)$ & $0 / 29(0)$ \\
\hline Preoperative incomplete RBBB & $2 / 20(10)$ & $0 / 10(0)$ & $0 / 3(0)$ & $2 / 7(29)$ & - \\
\hline Preoperative complete RBBB & $34 / 34(100)$ & $12 / 12(100)$ & $8 / 8(100)$ & $14 / 14(100)$ & - \\
\hline Ventricular septal defect & $2(0.13)$ & $0(0)$ & $0(0)$ & $2(0.38)$ & $0(0)$ \\
\hline Stroke & $6(0.38)$ & $0(0)$ & $2(0.47)$ & $4(0.77)$ & $1(3.4)$ \\
\hline Renal failure & $8(0.51)$ & $3(0.51)$ & $0(0)$ & $5(1.0)$ & $0(0)$ \\
\hline Postoperative length of stay (d) & $6.0(5.0-8.0)$ & $5.0(5.0-7.0)$ & $6.0(5.0-7.0)$ & $7.0(5.0-9.0)$ & $7.0(6.0-9.0)$ \\
\hline Operative mortality $\dagger$ & $6(0.38)$ & $2(0.34)$ & $0(0)$ & $4(0.77)$ & $0(0)$ \\
\hline
\end{tabular}

SD, Standard deviation; $L V O T$, left ventricular outflow tract; $R B B B$, right bundle branch block. *Septal myectomy with or without mitral valve intervention but with other concomitant procedure. †Hospital stay +30 days.

\section{Role of Mitral Valve Replacement in the Management of Left Ventricular Outflow Tract}

MVR was performed in $6 \%$ of patients in this series, with 1 death. Only 20 patients had an MVR as the sole operation for LVOTO. As such, our experience does not help elucidate the finding of higher mortality after MVR as described by Wei and colleagues. ${ }^{20}$ It is noteworthy that in a substantial proportion of patients, a biologic prosthesis was used.

\section{Pacemakers}

When the myectomy incision is initiated at the point of SAM septal contact, 1.5 to $2.0 \mathrm{~cm}$ below the right coronary cusp, patients with normal conduction should expect the likelihood of developing heart block requiring a pacemaker to be approximately $1 \%$. One might consider inserting epicardial leads and a pacemaker at the time of myectomy in patients with complete RBBB.

\section{Ventricular Septal Defect}

Creating an iatrogenic ventricular septal defect was rare despite aggressive resection of septal muscle. We believe this is a result of our close inspection of septal thickness on intraoperative TEE and tailoring the resection to the septal anatomy. In addition, mitral valve repair techniques can supplement the resection in patients with thinner septums or while the surgeon is gaining myectomy experience.

\section{Study Limitations}

This study is subject to all the limitations of a retrospective cohort study from a single institution. Additionally, the majorities of cases are not local and are referred from some distance. As such, long-term echocardiographic data were not available for a significant number of patients. Because the medium- and long-term durability of mitral valve interventions, rates of reoperations, and need for early postdischarge interventions such as pacemakers were not assessed, the event rates in this study may underestimate the true rates.

\section{CONCLUSIONS}

Our findings show that an experienced HOCM team with expertise in diagnosis, imaging, surgical technique, and postoperative care can safely and reliably relieve LVOTO with preservation of the mitral valve. Most patients with substantial hypertrophy will benefit from myectomy alone. Innovative repair techniques with or without a myectomy can eliminate LVOTO in patients with minimal or modest hypertrophy. 


\section{Webcast}

You can watch a Webcast of this AATS meeting presentation by going to: https://aats.blob.core.windows.net/ media/18Apr29/20ABC \% 202.Adult $\% 20$ Cardiac $\% 20$ SS \%20(PM)/S51\%20-\%20Part\%202/S51_7.mp4.

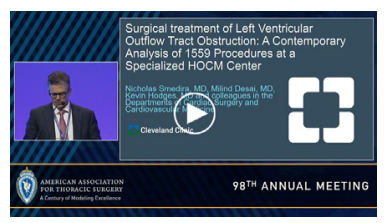

\section{Conflict of Interest Statement}

M.Y.D. is a consultant for MyoKardia. All other authors have nothing to disclose with regard to commercial support.

The authors thank Philip Wilson for the illustration of extended septal myectomy (Figure 1), Joe Pangrace for the illustration of commonly used mitral valve interventions (Figure 2), Tess Parry for editorial assistance, and Elizabeth Hejny for data retrieval.

\section{References}

1. Agarwal S, Tuzcu EM, Desai MY, Smedira N, Lever HM, Lytle BW, et al. Updated meta-analysis of septal alcohol ablation versus myectomy for hypertrophic cardiomyopathy. J Am Coll Cardiol. 2010;55:823-34.

2. Liebregts M, Vriesendorp PA, Mahmoodi BK, Schinkel AF, Michels M, ten Berg JM. A systematic review and meta-analysis of long-term outcomes after septal reduction therapy in patients with hypertrophic cardiomyopathy. JACC Heart Fail. 2015;3:896-905.

3. Smedira NG, Lytle BW, Lever HM, Rajeswaran J, Krishnaswamy G, Kaple RK, et al. Current effectiveness and risks of isolated septal myectomy for hypertrophic obstructive cardiomyopathy. Ann Thorac Surg. 2008;85:127-33.

4. Valeti US, Nishimura RA, Holmes DR, Araoz PA, Glockner JF, Breen JF, et al. Comparison of surgical septal myectomy and alcohol septal ablation with cardiac magnetic resonance imaging in patients with hypertrophic obstructive cardiomyopathy. J Am Coll Cardiol. 2007;49:350-7.

5. Panaich SS, Badheka AO, Chothani A, Mehta K, Patel NJ, Deshmukh A, et al. Results of ventricular septal myectomy and hypertrophic cardiomyopathy (from nationwide inpatient sample [1998-2010]). Am J Cardiol. 2014;114: 1390-5.

6. Kim LK, Swaminathan RV, Looser P, Minutello RM, Wong SC, Bergman G, et al Hospital volume outcomes after septal myectomy and alcohol septal ablation for treatment of obstructive hypertrophic cardiomyopathy: US nationwide inpatient database, 2003-2011. JAMA Cardiol. 2016;1:324-32.

7. Panaich SS, Patel N, Arora S, Patel NJ, Patel SV, Savani C, et al. Influence of hospital volume and outcomes of adult structural heart procedures. World J Cardiol. 2016;8:302-9.

8. Maron BJ, Dearani JA, Ommen SR, Maron MS, Schaff HV, Nishimura RA, et al. Low operative mortality achieved with surgical septal myectomy: role of dedicated hypertrophic cardiomyopathy centers in the management of dynamic subaortic obstruction. J Am Coll Cardiol. 2015;66:1307-8.

9. Hong JH, Schaff HV, Nishimura RA, Abel MD, Dearani JA, Li Z, et al. Mitral regurgitation in patients with hypertrophic obstructive cardiomyopathy: implications for concomitant valve procedures. J Am Coll Cardiol. 2016;68:1497-504.

10. Kwon DH, Smedira NG, Thamilarasan M, Lytle BW, Lever H, Desai MY. Characteristics and surgical outcomes of symptomatic patients with hypertrophic cardiomyopathy with abnormal papillary muscle morphology undergoing papillary muscle reorientation. J Thorac Cardiovasc Surg. 2010;140:317-24.

11. Patel P, Dhillon A, Popovic ZB, Smedira NG, Rizzo J, Thamilarasan M, et al. Left ventricular outflow tract obstruction in hypertrophic cardiomyopathy patients without severe septal hypertrophy: implications of mitral valve and papillary muscle abnormalities assessed using cardiac magnetic resonance and echocardiography. Circ Cardiovasc Imaging. 2015;8:e003132.
12. Yacoub M, Onuzo O, Riedel B, Radley-Smith R. Mobilization of the left and right fibrous trigones for relief of severe left ventricular outflow obstruction. $J$ Thorac Cardiovasc Surg. 1999; 117:126-33.

13. Kaple RK, Murphy RT, DiPaola LM, Houghtaling PL, Lever HM, Lytle BW, et al. Mitral valve abnormalities in hypertrophic cardiomyopathy: echocardiographic features and surgical outcomes. Ann Thorac Surg. 2008;85:1527-35. 1535 e1-2.

14. Zoghbi WA, Adams D, Bonow RO, Enriquez-Sarano M, Foster E, Grayburn PA, et al. Recommendations for noninvasive evaluation of native valvular regurgitation: a report from the American Society of Echocardiography developed in collaboration with the Society for Cardiovascular Magnetic Resonance. J Am Soc Echocardiogr. 2017;30:303-71.

15. Morrow AG, Brockenbrough EC. Surgical treatment of idiopathic hypertrophic subaortic stenosis: technic and hemodynamic results of subaortic ventriculomyotomy. Ann Surg. 1961;154:181-9.

16. Morrow AG, Reitz BA, Epstein SE, Henry WL, Conkle DM, Itscoitz SB, et al. Operative treatment in hypertrophic subaortic stenosis. Techniques, and the results of pre and postoperative assessments in 83 patients. Circulation. 1975;52:88-102.

17. Jiang L, Levine RA, King ME, Weyman AE. An integrated mechanism for systolic anterior motion of the mitral valve in hypertrophic cardiomyopathy based on echocardiographic observations. Am Heart J. 1987;113:633-44.

18. Maron MS, Olivotto I, Harrigan C, Appelbaum E, Gibson CM, Lesser JR, et al. Mitral valve abnormalities identified by cardiovascular magnetic resonance represent a primary phenotypic expression of hypertrophic cardiomyopathy. Circulation. 2011;124:40-7.

19. Nguyen A, Schaff HV, Nishimura RA, Dearani JA, Geske JB, Lahr BD, et al. Does septal thickness influence outcome of myectomy for hypertrophic obstructive cardiomyopathy? Eur J Cardiothorac Surg. 2018;53:582-9.

20. Wei LM, Thibault DP, Rankin JS, Alkhouli M, Roberts HG, Vermulapalli S, et al. Contemporary surgical management of hypertrophic cardiomyopathy in the United States [abstract]. 54th Annual Meeting of The Society of Thoracic Surgeons, Fort Lauderdale, Florida, January 28-31, 2018.

Key Words: septal myectomy, hypertrophic obstructive cardiomyopathy, mitral valve repair, transesophageal echocardiography, mitral valve pathology

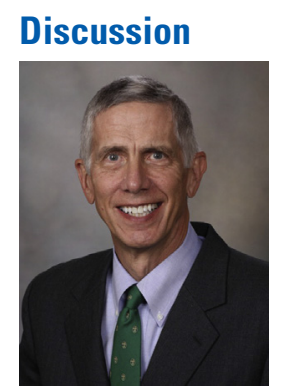

Dr Hartzell V. Schaff (Rochester, Minn). Nick, you demonstrated low operative mortality in more than 1500 patients undergoing septal myectomy and describe some important details of your surgical technique. Our experience in more than 3000 adults and children undergoing operations for hypertrophic cardiomyopathy is similar in some respects but differs in others, and I will mention a few of those before asking questions.

Your description and illustrations of the surgical technique depict a rather wide subaortic resection from trigone to trigone. We prefer to begin the septal myectomy just to the right of the nadir of the right aortic sinus and carry this leftward over to the anterior leaflet of the mitral valve, the area that you call the left fibrous trigone. We have not found it necessary to extend the myectomy rightward, and in fact this may have some disadvantage as regards conduction disturbance.

We believe the important technical point is that an adequate myectomy depends not on the width or the depth 
of the resection but on the length of the resection. In almost all cases who have been referred to us for repeat operation, the initial myectomy was not carried out far enough toward the apex of the heart.

So a tip for surgeons in the audience who are beginning the procedure: If you complete the myectomy and the postbypass echocardiogram shows that you have residual obstruction and SAM, don't default to a mitral valve procedure and don't make your myectomy deeper or wider. Rather, you should take it further, toward the apex of the heart.

The potential issue regarding surgical technique and conduction disturbances is reflected in the pacemaker rate of $4.2 \%$ and the near uniform need for a pacemaker in your patients who came to surgery with a preexisting RBBB; indeed, a preexisting RBBB is an important risk factor for heart block after myectomy. In our experience in patients with RBBB preoperatively, $36 \%$ require permanent pacing after transaortic septal myectomy.

In our practice, it's rarely necessary to perform a mitral valve procedure in the absence of intrinsic mitral valve pathology, and approximately $5 \%$ to $6 \%$ of patients who undergo myectomy will have ruptured chords or isolated leaflet prolapse that requires something to be done to the mitral valve. Of the remaining patients, at least in our practice, $98 \%$ can be treated with myectomy alone.

You also mentioned the issue of septal thickness and how this might influence the need for a mitral valve procedure. In our practice, $25 \%$ of patients have septal thicknesses less than $18 \mathrm{~mm}$ and two-thirds have septal thicknesses less than $21 \mathrm{~mm}$. But even in the cohort of patients with thin septa, the chance of needing a mitral valve procedure is $10 \%$. There may be some advantage in minimizing interventions on the mitral valve to minimize the risk of valve replacement, which has been necessary in our practice in $2 \%$ of patients.

Now, my first question is really for clarification. In your article, the bulk of the experience is for LVOTO, but you included 14 patients who had apical myectomy. We generally categorize these patients separately because the operation is performed to enlarge the left ventricle rather than to relieve obstruction. What were the indications and goals of operation in your patients having apical myectomy?

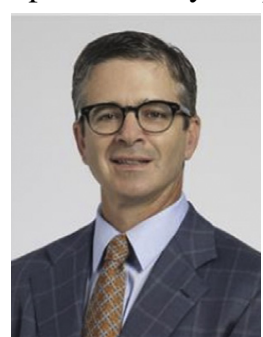

Dr Nicholas Smedira (Cleveland, Ohio). Those patients had both midventricular and apical myectomies. We performed the myectomies in those patients through a transaortic approach. I don't recall the exact number, but at least half also had LVOTO as part of that complex. So it was a combination of standard basilar mid cavitary and then extending all the way into the apex in a transaortic fashion.

Dr Schaff. Likewise, you included 41 patients who had subaortic membranes, and I presume this is different than the contact lesion on the septum from patients with HOCM and SAM. Myectomy is often performed with membranectomy in patients with membranous subaortic stenosis, but almost all of these patients have congenital sub-AS, and this is a different disease with fixed rather than dynamic outflow tract obstruction. Did all 41 patients with membranes have SAM of the mitral valve?

Dr Smedira. Yes.

Dr Schaff. I would like to explore a bit of this business of centers of excellence and surgeon experience, and you and I have discussed this before. You mention this in the abstract and the article as the keys to the good outcomes that you have shown. We agree in general with the proposition, but what constitutes a center of excellence and adequate surgeon experience? To paraphrase a Supreme Court justice who remarked on another subject, we know it when we see it. But surgeons in the audience may want a little more detail on your view of what an adequate surgical experience is and when does the mortality and good results show up in terms of number of patients operated on?

Dr Smedira. That's a great question, and, Hartzell, thank you for the questions and for your vast experience. I will get to the pertinent point last.

I think you need a multidisciplinary center. A big part of my learning curve was through the interaction with our imaging specialists, so understanding the complex and variable nature of the LVOTO. I think that's fundamental. There is also the need for accurate diagnosis and timing of treatment. That's part of the multidisciplinary center of excellence.

It's a challenge for me to figure out what number is necessary, because I think I'm still learning how to do this operation as I see the great variability as in the cases I showed you. My sense is you need approximately 50. I think that young surgeons interested in this area, and there is a great opportunity here, would benefit from a fellowship at your institution or at ours, because there is a great deal of nuance in treating the patients with outflow tract obstruction.

Dr Schaff. This issue of centers of excellence and how that plays into surgical results is complex, but you have been very modest. When you unpack aspects of a center of excellence to understand good surgical outcomes such as those you presented, the keys, of course, are good surgeons. Congratulations on this excellent series. 